\title{
Urgences
}

\section{Il voyait la vie...}

\section{Lecomte D'Arcy}

Numéro 20, mai 1988

Appellation contrôlée

URI : https://id.erudit.org/iderudit/025464ar

DOI : https://doi.org/10.7202/025464ar

Aller au sommaire du numéro

Éditeur(s)

Urgences

ISSN

0226-9554 (imprimé)

1927-3924 (numérique)

Découvrir la revue

Citer ce document

D'Arcy, L. (1988). Il voyait la vie... Urgences, (20), 14-14.

https://doi.org/10.7202/025464ar

Ce document est protégé par la loi sur le droit d'auteur. L'utilisation des services d'Érudit (y compris la reproduction) est assujettie à sa politique d'utilisation que vous pouvez consulter en ligne.

https://apropos.erudit.org/fr/usagers/politique-dutilisation/
Cet article est diffusé et préservé par Érudit.

Érudit est un consortium interuniversitaire sans but lucratif composé de l’Université de Montréal, l'Université Laval et l'Université du Québec à Montréal. Il a pour mission la promotion et la valorisation de la recherche. https://www.erudit.org/fr/ 


\section{LECOMTE D'ARCY}

à Sophie, Shetan Bogat, Fosco Sinibaldi, Ossian, Yakov, Greenwood et Tadeusz Roman Cisowski,

Il voyait la vie comme un voyage dans l'espace-temps, mais il avait des haut-le-coeur, car il croyait qu'en cette année du double infini, la navette s'était égarée dans une sorte de trou noir que même l'apesanteur ne savait amoindrir. Tous venaient de relire le manuel amémoriel et l'on en était à constater que l'on approchait certainement des conditions idéales, celles qu'on n'aurait pas osé imaginer à l'époque où ce code avait été rédigé. Déjà, chaque membre de l'équipe avait de la difficulté à se reconnaître, autant dans un miroir que sur sa propre carte d'identité. La grève générale par oubli serait donc déclarée, mais pas par vote populaire comme on l'espérait. Seules les conditions la provoquaient. Tout ce qui restait encore possible d'établir était qu'il y avait un faux ressortissant juif, un pseudo irlandais venu du futur ainsi qu'un ancien aristocrate français qui avaient jadis programmé une certaine machine à mots sans commencement ni fin. Et sans doute, dans les prochaines secousses, ces dernières informations disparaîtront-elles à leur tour.

Par le vitrail, on voyait des éclipses et le fond de l'air restait désespérément noir. La situation avait de quoi équarrir n'importe quel absolu, car le dé de la nuit avait été jeté dans les esprits anéantis. Quelque part à côté du mystère, Babylone était dans les mémoires avec tous ses dialectes entrecroisés, toute anecdote devenant donc impossible à reconstituer, comme si soudain les archivistes se faisaient distraits.

Autrement dit l'équilibre n'était plus pensable, le chant des mots et des images s'était perdu entre ce qu'il y avait d'inerte dans le clameur des souvenirs. Quelqu'un avait dit que tout devait disparaître, même les signatures. Désormais la matière était en émeute et chaque instant aléatoire dans son inédit barbare. Aucun exit, aucun timbre. Maintenant: le désert, et catégorique. 